University of Montana

ScholarWorks at University of Montana

Public and Community Health Sciences Faculty

Publications

Public and Community Health Sciences

$11-2010$

\title{
Translating the Diabetes Prevention Program for Northern Plains Indian Youth Through Community-Based Participatory Research Methods
}

\author{
Blakely D. Brown \\ University of Montana - Missoula, blakely.brown@mso.umt.edu \\ Kari J. Harris \\ University of Montana - Missoula, kari.harris@umontana.edu \\ Jeri Lyn Harris \\ Crow Agency, Montana \\ Martin Parker \\ Rocky Boy Trial Health, Montana \\ Christiana Lea Ricci \\ The University of Montana, christiana.ricci@gmail.com \\ Follow this and additional works at: https://scholarworks.umt.edu/pchs_pubs \\ See next page for additional authors \\ Part of the Public Health Commons \\ Let us know how access to this document benefits you.
}

\section{Recommended Citation}

Brown, Blakely D.; Harris, Kari J.; Harris, Jeri Lyn; Parker, Martin; Ricci, Christiana Lea; and Noonan, Curtis W., "Translating the Diabetes Prevention Program for Northern Plains Indian Youth Through CommunityBased Participatory Research Methods" (2010). Public and Community Health Sciences Faculty

Publications. 36.

https://scholarworks.umt.edu/pchs_pubs/36

This Article is brought to you for free and open access by the Public and Community Health Sciences at ScholarWorks at University of Montana. It has been accepted for inclusion in Public and Community Health Sciences Faculty Publications by an authorized administrator of ScholarWorks at University of Montana. For more information, please contact scholarworks@mso.umt.edu. 
Authors

Blakely D. Brown, Kari J. Harris, Jeri Lyn Harris, Martin Parker, Christiana Lea Ricci, and Curtis W. Noonan 


\title{
Translating the Diabetes Prevention Program for Northern Plains Indian Youth Through Community-Based Participatory Research Methods
}

\author{
Dr. Blakely D. Brown, PhD, RD, Dr. Kari Jo Harris, PhD, Ms Jeri Lyn Harris, Mr Martin \\ Parker, BS, Ms. Christiana Ricci, MS, and Dr. Curtis Noonan, PhD \\ Department of Health and Human Performance (Dr Brown, Ms Ricci), School of Public Health \\ and Community Health Sciences (Dr K. J. Harris), and Center for Environmental Health Sciences \\ (Dr Noonan), University of Montana, Missoula; Crow Tribal Health Diabetes Program, Crow \\ Agency, Montana (Ms J. L. Harris); and Rocky Boy Tribal Health, Box Elder, Montana (Mr Parker)
}

\begin{abstract}
Purpose-The purpose of this study was to use a community-based participatory research (CBPR) approach to translate the original Diabetes Prevention Program (DPP) to be age and culturally specific for American Indian (AI) youth.
\end{abstract}

\begin{abstract}
Methods-Tribally enrolled members on 2 Montana Indian reservations conducted focus groups and interviews to discuss community members' perspectives of factors that encouraged or were barriers to healthy diet and exercise behaviors in AI youth. In total, 31 community members, aged 10 to 68 years old, participated in 4 focus groups and 14 individual interviews. Participants were self-identified as elder, cultural expert, tribal health worker, educator, parent/guardian, youth, or school food service worker. Researchers analyzed transcripts based on inductive methods of grounded theory.
\end{abstract}

Results-Data analysis revealed translating the DPP to youth was contingent on the lessons incorporating cultural strategies for healthy behaviors in youth such as berry picking, gardening, horseback riding, and dancing; improving knowledge and access to healthy foods and physical activity for youth and their parents; having interactive, hands-on learning activities for healthy lifestyles in the DPP lessons; using a group format and tribal members to deliver the DPP lessons; and having tribal elders talk to youth about the importance of adopting healthy behaviors when they are young.

Conclusions-A CBPR approach engaged community members to identify strategies inherent in their culture, tradition, and environment that could effectively translate the DPP to Montana Indian youth living in rural reservation communities.

Overweight in childhood is a major risk factor for type 2 diabetes. In 2008, obesity prevalence was highest among American Indian/Alaska Native (AI/AN) preschool children $(21.2 \%)$ compared to non-Hispanic white $(12.6 \%)$ or non-Hispanic black (11.8\%) children. ${ }^{1}$ The prevalence of overweight and obesity among American Indian children ages 5 to 17 living in the Northern Plains region of the United States is reported to be 2 to 4 times the national average. ${ }^{2,3}$ Investigators ${ }^{4-6}$ propose that alterations in American Indian lifestyles, such as increased sedentary behaviors and the "Westernization" of the American Indian diet

(C) 2010 The Author(s)

Correspondence to Blakely Brown, PhD, RD, 207 McGill Hall, Department of Health and Human Performance, University of Montana, 32 Campus Drive, Missoula, MT 59812 (blakely.brown@ mso.umt.edu).

For reprints and permission queries, please visit SAGE's Web site at http://www.sagepub.com/journalsPermissions.nav. 
(eg, high fat and total energy), have contributed to the epidemic of type 2 diabetes in American Indians. ${ }^{7-11}$ Evidence from observational and interventional studies, ${ }^{12-17}$ as well as from school-based curriculum programs, ${ }^{18,19}$ suggests that behavioral approaches to increase daily physical activity and modify dietary intake of total fat can reduce risk factors associated with diabetes such as overweight and obesity.

The 7 Indian reservations in Montana are part of the Northern Plains region of the United States. American Indians comprise $6 \%$ of the state's population. The prevalence of diabetes in Montana Indian adults is $16 \%$, which is nearly 3-fold higher than non-Indian populations in Montana. ${ }^{20,21}$ Although few $(0.23 \%)$ Northern Plains Indian youth $(<20$ years old) have yet to develop type 2 diabetes, ${ }^{22}$ nearly all exhibit risk factors, which include ethnicity, family history of diabetes, and parental overweight or obesity. A change in lifestyle, such as diets emphasizing healthful foods and increased physical activity, has the potential to reverse the modifiable risk factors and prevent or delay the development of type 2 diabetes.

The Diabetes Prevention Program (DPP) was a multi-center clinical trial randomizing 3324 nondiabetic adults with elevated fasting and postload plasma glucose concentrations to placebo, medication (metformin), or a lifestyle modification program. ${ }^{23}$ The lifestyle modification arm of the study primarily focused on achieving and maintaining a weight reduction of at least $7 \%$ of initial body weight through healthy dietary intake and engaging in physical activity of moderate activity for at least 150 minutes per week. After nearly 3 years, results showed the incidence of diabetes reduced in the lifestyle intervention by $58 \%$ and medication by $31 \%$ as compared with placebo, and the lifestyle intervention was significantly more effective than medication. ${ }^{14}$ Minority groups who suffer disproportionately from type 2 diabetes (African Americans, Hispanic Americans, Asian Americans and Pacific Islanders, and American Indians) made up $45 \%$ of the participants enrolled in the DPP study. ${ }^{23}$ The lifestyle modification worked equally well in men and women in all the ethnic groups. These findings show the DPP provides an effective model program on which to base lifestyle interventions to prevent diabetes.

Translation refers to the process through which new science (such as the evidence-based DPP) is used to improve the nation's health. ${ }^{24}$ Phase II translation includes effectiveness trials whose goal is to evaluate promising clinical research in disparate settings, populations, and circumstances. Although the DPP has not been translated to youth, it has been translated to adults in a variety of settings, including YMCAs, ${ }^{25}$ primary care practice settings, ${ }^{26-29}$ community health care settings, ${ }^{30,31}$ and faith-based locales. ${ }^{32-34}$ These studies have used DPP intervention experts, ${ }^{26,29-31,35}$ clinicians, ${ }^{27,28}$ community organization staff, and academic researchers $^{35}$ or focus group participants $33,34,36$ to translate the DPP sessions to adults in the program delivery setting. Although none of the DPP translational studies were for American Indians, some were for adults at disproportionate risk for diabetes such as African Americans, ${ }^{33,36,37}$ Latina and African American women, ${ }^{34}$ and adults in an urban medically underserved community. ${ }^{31}$

The studies using focus groups to translate the DPP into their communities reported several common themes. ${ }^{33,34,36}$ All studies found community members had a strong interest in making lifestyle changes to prevent diabetes and recommended that a small group format be used to implement the program in local churches, ${ }^{33,34,36}$ schools, or community centers. ${ }^{34}$ Focus group participants recommended these small DPP group workshops have hands-on learning activities, testimonials from people with diabetes, and prevention literature and identify a support system or have people with diabetes act as peer coaches. ${ }^{36}$ Through the focus group discussions, investigators were made aware of challenges adults face to making lifestyle changes, such as unrealistic goals for behavior changes, no support and environmental barriers for exercising regularly, or not enough time for exercise or making 
healthy meals. ${ }^{34,36}$ Understanding these barriers to behavior change and including strategies that address these specific challenges helped translate the DPP into a more effective approach for preventing diabetes in these communities.

A community-based participatory research (CBPR) approach brings together communities and researchers to improve health collaboratively in the community and may be an especially useful approach in vulnerable, hard-to-reach populations. ${ }^{38} \mathrm{CBPR}$ actively engages the community in all aspects of the research process, ${ }^{38}$ builds upon existing community strengths, ${ }^{39}$ and may hold significant promise for implementing effective and sustainable public health approaches. ${ }^{24}$ By promoting long-term, equitable partnerships between researchers and communities, CBPR approaches can create a balance between the scientific rigors of tightly controlled researcher-driven studies with the respect for indigenous wisdom about the local situation. Thus, a CBPR approach was used to translate the adult DPP to youth living in reservation communities.

The objective of this study was to solicit community members' perspectives of factors that encouraged or were barriers to healthy diet and exercise behaviors in Northern Plains Indian youth. The main themes and strategies identified from tribal community focus groups and interviews will be used to adapt the original DPP to be age and culturally specific for Northern Plains Indian youth. The University of Montana Institutional Review Board approved the study.

\section{Methods}

This study used a CBPR approach to engage tribal and nontribal members of 2 communities in the Northern Plains Indian reservations. The CBPR framework allowed the academic researchers and community members to work together to identify behavioral and environmental factors that encourage or stem eating healthful foods, physical activity, and diabetes prevention awareness for translating the DPP to AI youth. The defining feature of CBPR is involvement and power sharing with community members in all phases of a project, from deciding what problem to address, assessing the need, planning, action, and evaluation. The data presented in this report describe the focus and interviews that were conducted during the first year of the study to adapt the DPP to AI youth. The focus groups and interviews, however, were one of many phases in this CBPR study. Below is a brief description of the overall CBPR project.

In the mid-1990s, tribal councils on both reservations made reducing the risk of diabetes in youth a priority in their communities. At the same time, national concern was growing for the rising rates of childhood overweight and obesity. Two of the investigators in the current study (BB, CN) have been assisting tribal health staff to collect and analyze annual health measures for assessing risk factors for diabetes in kindergarten to 12th-grade students attending schools on or near the reservations. These data are disseminated to community members and helped further identify youth at risk for overweight/obesity and diabetes in the community. ${ }^{2,40}$ In 2004, tribal health center staff and clinicians, as well as local tribal health board and council members from both reservation communities, met with University of Montana academic researchers to discuss forming a partnership to prepare and submit a National Institute of Diabetes, Digestive and Kidney Disease grant to fund translational research in reducing risk of childhood overweight/obesity. Subsequently, the partnership had a series of meetings during the next 9 months to collaboratively write the grant proposal and establish a Code of Research Ethics for the partnership and research study. Community members (MP, JL) and academic researchers (BB, $\mathrm{KH}, \mathrm{CN}$ ) were involved in discussions about study design issues, subject recruitment, evaluation strategies, and planning for longterm sustainability of the DPP-for-youth project. When the grant was funded (spring 2007), 
local community advisory boards (CABs) were established to provide input to the research team on the cultural aspects of the study. Throughout the study, academic and community researchers met with the CABs and tribal health directors and staff on a regular basis to keep members informed of the study's progress and outcomes. Parents/guardians of the children participating in the pilot study of the DPP-for-youth receive results of the study and followup discussion from local community researchers and diabetes prevention staff. Currently, the research partnership is submitting proposals to fund the implementation of the DPP for youth to at least 500 fifth-, sixth-, seventh-, and eighth-grade students on the 2 Northern Plains Indian reservations.

The 2 reservation communities are located more than 75 miles from the nearest city of 50 000 residents. The 2000 US Census reports that the communities, respectively, had 2676 and 6894 residents who were $96 \%$ and $75 \%$ Native American. ${ }^{41}$ Approximately $84 \%$ of youth in both communities were eligible for free and reduced lunches. ${ }^{42}$ Although the communities were similar in many respects, there were differences in recreational facilitates. One had a large, new indoor fitness center with a variety of exercise machines and a swimming pool. The other had a smaller, older fitness center without a swimming pool and a second small gym.

Two indigenous study staff members conducted focus groups and interviews in their respective communities from January to July 2007 . In total, 31 community members participated in 4 focus groups and 14 individual interviews. Study staff recruited participants through local elementary schools, tribal health clinics, colleges and community events, and by word of mouth. These diverse recruitment strategies allowed the authors to collect information from community members heterogeneous with respect to age, tribal affiliation, and position in the community (eg, elder, educator).

Four focus groups were conducted with a total of 17 participants, most of whom were American Indian. The size of the focus groups ranged from 2 to 6 participants. Because this study was particularly interested in the views of youth, 3 focus groups (with a total of 12 participants) comprised fifth- through eighth-grade students. One focus group (with a total of 5 participants) comprised adults who ranged in age from 24 to 68. Fourteen individual interviews were conducted with community members who were identified by project staff or other community members as knowledgeable about youth health. All interviewees were Native American and self-identified as elder, cultural expert, tribal diabetes coordinator, educator, school administrator, tribal health worker, parent/guardian, youth, or school food service worker.

Prior to facilitating the sessions, team members received training in qualitative methods, including conducting mock focus groups and interviews followed by feedback. The research team constructed a moderator's guide that included 15 open-ended questions. The guide was reviewed by local tribal members and manuscript authors trained in qualitative research (BB, KH). Example questions included the following: "What do you think keeps kids from being active on this reservation?" "What are some things that could motivate kids to be more active?" "What things on the reservation encourage kids to eat foods that are low in sugar and fat?" "How do adults and elders support or promote eating healthful foods during childhood and adolescence?" and "Where do kids get most of their nutrition and health information?" The moderator's guide also included discussion rules, recommendations for probing, and a time sequence.

Sessions were audiotaped, and the facilitator wrote summaries after each session. Session length ranged from 60 to 90 minutes. Six sessions were not recorded due to technical problems, and 1 interviewee declined to be recorded. Participants were provided a meal or 
snack and a modest cash reimbursement for participating. The moderators took detailed notes in all the sessions, especially the sessions that were not recorded. Immediately following each session, the moderator reviewed and clarified the written notes and summarized the comments by topic (physical activity, nutrition and diabetes prevention education).

Audiotapes and session notes were transcribed and formed the basis for analysis. The first 2 authors (BB and $\mathrm{KH}$ ) constructed coding categories based on the inductive methods of grounded theory ${ }^{43}$ with the aid of a qualitative analysis software program (NVivo 7, QSR International, Cambridge, MA). To construct the initial coding scheme, the first author (BB) reviewed transcripts from a selection of 6 sessions and developed a draft coding frame. Another member of the research team $(\mathrm{KH})$ applied the initial coding frame to text in one randomly selected transcript to determine reliability of the initial coding scheme. The overall agreement between raters was $81 \%$ (39/48), with Cohen's kappa significantly higher than expected by chance $(\kappa=.820)^{44}$ and representing almost perfect agreement. ${ }^{45}$ Because the initial coding scheme showed high reliability, it was used for the remainder of the study. When codes were discrepant across coders, researchers discussed discrepancies until agreement was reached. The authors corrected minor grammatical inaccuracies in the quotes presented to illustrate the themes.

\section{Results}

Analysis of the focus group and interview sessions identified common themes for behavioral, environmental, and social factors associated with diabetes risk in youth. These themes included general attitudes about diabetes and factors that encouraged or hindered eating healthful foods and physical activity in Northern Plains Indian reservation communities.

\section{Behavioral, Social, and Environmental Factors for Eating Healthful Foods}

Participants identified several factors associated with eating healthful foods in youth. These responses fell into 4 categories: home and nonschool environments, access to healthy foods, mind-set about eating healthful foods, and school food environments.

Home and Nonschool Food Environments-Many participants commented on the challenges parents face when attempting to provide healthful meals for their children such as lack of time, personal eating patterns, and lack of education about healthful food choices. A parent said, "There's not enough time, ... you work from eight to five ... you want things quick and easy, you know there's microwave meals, you can have a meal in four minutes ... and you know microwave meals aren't really healthy for you." Illustrating another dimension, a participant stated, "I think that parents that are not home when their kids get home, I think the kids fill up on junk food because there's nobody there." An adult tribal member commented on parents' good intentions but lack of nutrition knowledge. Parents also believed that eating snacks and junk food along with watching television and using computers creates a major obstacle to healthy eating.

Participants also identified several strategies to help parents provide healthful meals for their children. Participants thought community members could help develop healthful recipes and cookbooks for common foods available on the reservation and having these materials available for tribal members. Restricting access to unhealthful foods at home was also mentioned. An elder said, "If I don't have sugar in the house then it's not being eaten." A number of strategies to help parents serve nutritious meals at home were suggested. The main points included teaching parents how to prepare healthful foods, how to cook with 
commodity foods, education about portion sizes for youth, how to buy low-cost healthful food, and the importance of family meal time.

Some participants identified that the lack of adult role models for good nutrition was a concern. A cultural educator suggested, "It would be nice if the school maybe like once a week would have a community feed day, where you can come and see what the kids are eating, plus have the kids see that our parents and our elders want the best for us."

Participants recommended a number of changes to their food environment, including moving healthful food to the front of convenience stores, adding displays and marking of food as "health friendly," featuring health foods of the week, having a health food store, and selling prepackaged healthful sandwiches and water in convenient locations. One participant suggested, "Maybe the store could ... provide Subway sandwiches to sell right here at the convenience center and have them right up front with bottle of water."

Access to Healthy Foods-Lack of access to healthful foods was identified as a barrier to eating healthful foods. In talking about this barrier, a participant stated, "It's what's available. Access again is huge. We don't have nice grocery stores right here [on the reservation], we just have a little FoodMart and the convenience center over here." The participant then described how a friend bought lunch items from the local convenience store that were "all these candy bars, chips and pops and several cans of pop ... and that was actually her lunch ... that's what was available and convenient and probably affordable." The participant closed this part of the interview stating, "Maybe we could request the express center to provide some fresh fruits, maybe some salads." Reservation commodity foods were also seen as a barrier to eating nutritious foods. One adult said, "One problem is, to eat healthy, you need a lot of fresh fruits and vegetables and that's tough to do with commodity food."

Mind-Set About Eating Healthy Foods-Participants also thought mind-set and attitude toward eating a certain way was a barrier to eating healthful food. A school teacher said, "Younger and younger kids are starting to eat junk food and you don't have them develop the taste for healthy foods." Another aspect of family influence included showing care and love through food. An elder commented, "Being a grandma you know I want to give my grandkid what they want to eat not what they should eat."

School Food Environment-The school food environment was also discussed in several interviews and focus groups. Particularly salient were the food changes that had been implemented in one community's school. Several students, teachers, and elders commented that the salad bar was a strength of the school lunch program and that the school menu provided the most nutritious meals of the day. There was strong agreement that when kids eat healthful meals at school, they are less likely to eat unhealthful foods at home and become more accustomed to eating healthful foods. A parent said, "In school the kids really like the salad bar because it's all you can eat. The kids know what healthful foods are so they don't really pig out at home."

Both communities have made changes in their school environment to encourage eating healthful foods such as having only water and $100 \%$ juice and healthful snacks in school vending machines and not allowing students to leave school property during lunch to restrict access to fast foods. Despite these changes, participants reported that youth can easily access low nutritious foods through alternative means, including having their parents authorize them to leave school campus and go to the local convenience store where they buy pop, chips, and candy for themselves and their friends. 
A few participants identified small food portions at lunch and having no afternoon school snack led to students being hungry after school. In the words of one participant, "The kids really pig out when they get home because they do go home hungry."

\section{Factors Associated With Physical Activity in Youth}

Participants suggested ways for youth to be more active. These responses fell into 3 main categories: suggested activities and community resources, distance to recreational facilities and the physical environment, and group and traditional lifestyles for physical activity.

Suggested Activities and Community Resources-Participants suggested several activities that could be made available in the communities (Table 1). Suggestions included enhancing the organized sports programs and adding new activities that have a traditional and native focus and those that capitalize on the outdoor environment during the winter and summer. A number of participants noted there were many students not participating in organized sports and mentioned ways to engage them in alternative activities. Strategies included promoting activities that are fun and easy to start and do not involve contact sports or competition. Bike riding, sledding, and walks with family were examples. A tribal health outreach worker said, "You don't have to be an athlete to be healthy and fit." Some mentioned there was perhaps an overemphasis on basketball that might only support the activity of a small number of very fit youth. A school teacher commented, "They put a lot of money into basketball tournaments and that's the only activity that is actually offered for the kids. And we're not reaching all the activities that the other kids might be interested in. Then you have to think of other sports besides basketball."

Participants acknowledged that some excellent resources exist to support indoor or organized physical activity near their communities. Examples include fitness centers, weight room, rodeo grounds, and swimming pools. However, several participants suggested ways to improve these resources. Suggestions included having activities and staff available to assist children to engage in more opportunities to exercise. This would necessitate changing rules that currently prevent those younger than 16 years old access to the facilities. A tribal health employee said, "The pool's set up for 16-year-olds and we have a lot of obese kids too who really need the exercise."

Distance to Recreational Facilities and the Physical Environment-Long work hours of parents and the distance (up to 30 miles one way) and cost of travel to recreational facilities are also a barrier for children and families. Harsh weather makes winter and spring travel treacherous, and no public transportation exists in either community. A strategy used by one health worker was to "pick 'em up and take 'em home [after group activities]."

Some participants discussed how the physical environment itself does not support outdoor exercise very well. Lack of sidewalks, cars that travel too fast, dogs, snakes, and wood ticks in off-road walking areas make exercising outside difficult. As put by one coach, "But once the snakes come out we don't take that route any-more.... If something could be done with the rattlesnakes it would be good." Harsh winter conditions (deep snow, wind chill, and temperatures well below zero) also prevent exercise outdoors for 4 or more months of the year. In one of the communities, people had concerns about the rivers being polluted with toxic metals from mining operations located near the reservation. This concern keeps youth from swimming and recreating in the reservation's rivers and lakes during the summer.

Group and Traditional Lifestyles for Physical Activity-There was a lot of discussion about the value of exercising with others. Group activities encourage others to be more active, such as round dances where singing, dancing, and socializing are embedded. 
Social activities also help community members maintain their interest in exercise, such as walking groups. Participants described activities that involve youth and their family, especially extended family members, as particularly powerful motivators. An elder commented that "[My granddaughter] doesn't like to move, but her aunts will come and get her or her cousins, you know, and they'll go and she'll go swimming ... she likes to rock climb and one of my boys and grandsons are really into rock climbing. And she is pretty active so I figure she's moving anyway."

Participants also mentioned that the loss of a traditional lifestyle that included daily chores (such as carrying water and chopping wood) has reduced youth level of activity. Similarly, the addition of new electronic activities (eg, PlayStations, Xboxes, computer games, and television) results in more sedentary behavior. In the words of one community health care provider, "It's the video games, movies, you know, all of that stuff that really, really does harm to our kids."

A number of the activities mentioned involve the natural environment and traditional activities, such as sledding, berry picking, horseback riding, arrow throwing, and planting sweet grass. Although these activities do not require intensive resources (such as new buildings), they do require time and effort to organize as well as specialized knowledge of cultural traditions.

\section{General Attitudes and Beliefs About Diabetes and Prevention Strategies}

Toward the end of each focus group, interview moderators described the adult DPP to the participants and asked questions about their attitudes and beliefs about diabetes and potential settings for translating the DPP to youth in their communities. Responses fell into 2 categories: diabetes prevention awareness and including cultural traditions within the DPP sessions for youth.

Diabetes Prevention Awareness-There was widespread knowledge about diabetes and its risk factors and agreement for the critical importance of addressing these risk factors, especially among youth. A number of participants mentioned how common diabetes is on the reservation. Many described that youth learn about diabetes from their family and friends. "I learned from my grandmother because at first she was controlling it by exercising and eating. And I remember when she went out on walks she always made us go with her, so I knew that she was diabetic. And along the way it got to a point where she had to check on her blood [sugars]. So through her, that's where I learned [about] diabetes."

Participants were interested in having an adapted DPP for youth in their communities. The participants said implementing the lifestyle modification program would probably work best at schools, fitness or diabetes program centers, and outreach clinics. Participants were skeptical that the program could be successfully run during the summer due to people traveling for vacations and powwow events. A few of the tribal health workers interviewed talked about various educational efforts that have occurred in schools over the years to educate youth about diabetes. Some thought that youth were becoming more knowledgeable about diabetes and foods with fats and sugars that might be associated with risk for the disease. Participants said teaching the diabetes prevention strategies would be most effective in a small group format.

Although there was widespread agreement among the participants for the need to translate the adapted lifestyle modification program for youth on their reservations, some acknowledged that many tribal members feel that developing diabetes is "unavoidable." Expressing this concern, one teacher said, "Kids understand the risk factors, but they also kind of have the attitude that there is nothing [they] can do about it. I'm Native American, 
my family has diabetes, I'm going to get diabetes. And that needs to change. They need to realize they can prevent it and they need to start now." In response to these concerns, participants thought educating youth about diabetes should begin early in life and that parents needed to be educated about diabetes too. A community health nurse said, "Diabetes prevention should be taught as soon as kids enter school. Kids are never too young to learn." A school teacher added, "Everything needs to start from the home; once you educate the parents then the parents will start educating the kids."

Including Cultural Traditions Within the DPP Sessions for Youth-Several participants talked about the importance of including Northern Plains Indian cultural and historical resources, stories, and activities in the diabetes prevention curriculum. For example, having spiritual leaders and elders teach youth about traditional ceremonies and foods would be one way to help children and adolescents grow up to be healthier people. One elder said, "It would help the kids if they would be part of putting up a sweat lodge. I see a lot of sweats going up, but [kids] don't know what the meaning is of building sweats." Another language teacher said, "There are a lot of ceremonies that involved food, you know there are a lot of kids who don't even know how to serve food in a culturally appropriate way." Another elder said, "Offer some kind of program where you are doing the cultural part of it too, learning how to cook, you know, dry meat and stuff like that, tanning hides for making drums, lighting sweet grass and smudging."

Riding horses was identified as an important foundation for spirituality and health. A tribal diabetes outreach educator said, "Our spirituality is the foundation, but being with that horse and riding is part of spirituality. The Plains Indians lived everyday with riding their horses in the hills and that feeling you get from that is the most awesome feeling to run, just to run out there in the hills, on a horse, is just wonderful ... and a lot of our children have never felt that. You have a real connection to the ground, with the animals. When you're in a car you got your music on real high, you're totally cut off from the world, and that energy that you get from the ground through your horse to you, and the air and the sunshine, you can't get that riding in a car."

\section{Discussion}

The focus group and interview discussions brought together people living on Northern Plains Indian reservations interested in health and diabetes prevention to discuss potential barriers, enhancers, and resources for translating the DPP to youth in their communities. As described above, these discussions were embedded within the overall CBPR process used in the study, which included involvement and power sharing with community members from both reservations in all phases of the project. The following discussion compares this study's findings with prior studies and gives suggestions for translating the DPP to American Indian youth.

Data analyses revealed a high interest in preventing diabetes in youth. Participants were eager to find ways to promote youth activity and healthier eating habits. There was overall agreement that several enhancers for youth adopting more healthy behaviors exist, such as knowledge of the high prevalence of diabetes in the community stimulates interest in implementing prevention programs at an early age; that having group and community activities for healthier eating and physical activity can motivate youth to adopt these behaviors; and that the ease of obtaining high-fat, high-calorie foods and watching television and playing computer game habits were challenges to youth exercise. The findings in this study are similar to prior studies adapting diabetes prevention strategies, which acknowledged the importance of understanding the potential for preventing or delaying diabetes as a stimulus for action, ${ }^{46}$ that social support and communal ties can strongly 
reinforce adapting healthy lifestyles, ${ }^{34,36,46}$ and that time constraints, fast food, and sedentary entertainment can be major obstacles to lifestyle change. ${ }^{34,46}$ This study also found a high level of general awareness about the importance of making lifestyle changes to decrease the risk for diabetes. This finding agrees with others determining the importance of disease prevention in disadvantaged communities ${ }^{34,36}$ and in a Canadian aboriginal community. ${ }^{47}$

The data in this study highlighted the important role that parents and community members have on youths' food intake and physical activity. Many participants reported that parents lacked time or energy to engage in family physical activity or prepare homemade meals. These findings are similar to other studies reporting that barriers to regular exercise were women returning home tired from work and/or home responsibilities and falling into the sedentary pattern of watching television to relax, ${ }^{34}$ or how squeezed parents are for time and thus depend on low-nutrition, high-calorie fast foods to feed their families. ${ }^{46}$

Focus group participants also mentioned the importance of having more adult role models and community members mentor good nutrition and physical activity habits to youth. These results are similar to prior studies seeking community input for perceptions about diabetes prevention $^{46,47}$ that showed that social support and communal ties in American Indian communities appeared to be the strongest reinforces for adapting healthy lifestyle behaviors for preventing diabetes.

In this study, the authors also compared their findings to studies that have explored parents' and adolescents' suggestions for healthful lifestyles but were not specific to translating the DPP to youth. ${ }^{48-50}$ This study's findings are similar to these prior studies, which identified parents having a strong ${ }^{48,49}$ or moderate ${ }^{50}$ influence on youth for eating and physical activity behaviors. These results support having the DPP-for-youth program include information for parents describing ways to prepare healthy meals, as well as find time for family and community activities throughout the year and alternatives to watching television. Youth participating in the DPP sessions could take these materials home and discuss this information with their parents. DPP lifestyle coaches could organize monthly community walks or bike rides that involve youth and their family members. This would help engage parents and community members in the lifestyle modification program and increase their interest to role model good physical activity habits to youth.

Although lack of access to healthy foods on the reservation was identified as a barrier to healthy eating, there was interest in learning how to obtain commodity food packages that have fresh fruits and vegetables, whole-grain flours and cereals, and low-sugar and lowsodium canned foods. These findings contrast with other reports that did not identify a strong interest in learning about purchasing healthy foods using Food Stamps or WIC (Women, Infants and Children) coupons ${ }^{34,36}$ or through American Indian governmental food programs. ${ }^{46}$ Information about healthy foods available in the commodity food packages could be included in the translated DPP-for-youth program. Families could review this information to identify healthy foods they could get through local food assistance programs.

Participants commented on the school nutrition environment and how this affects healthy eating in youth. Participants agreed that if youth eat healthy meals at school, they are more likely to eat healthy foods away from school and that having salad bars at schools improved school lunch programs. These findings are hard to compare to other studies using focus groups to translate the DPP to their community settings because questions were not asked about the role the school environment plays on youths' eating habits. ${ }^{33,34,36}$ However, this finding does contrast with studies that have elicited child and parent views regarding social 
and environmental barriers to healthy eating and child obesity prevention. ${ }^{48,50,51}$ Specifically, parents and caregivers in the study by Styles et $\mathrm{al}^{51}$ talked about schools undermining healthy eating habits through food choices offered in cafeteria lunches and classroom snacks, as well as rewards provided in classrooms. An Australian study showed that many foods that children are taught to recognize as unhealthy are available at the school cafeteria, resulting in some children believing that "they' re not really bad for you." 48 Still others discussed the food available in the school cafeteria and described fruits and vegetables as looking bruised and unappealing and the lines for the more healthful foods as too long. ${ }^{50}$ That school meals were identified as "healthy" in this study is encouraging evidence that the community may have successfully modified the school food environment.

Participants thought more strategies need to be implemented that discourage youth from accessing unhealthy foods when they leave the school campus during lunch-time or other times during the school day. Therefore, the translated DPP could include activities and information for youth (and their parents) on how to shop for healthy foods and snacks at convenience stores on the reservations and the health consequences of eating high-fat, highcalorie snacks and beverages compared to eating fruits and vegetables available at school lunch salad bars. Similarly, some of the DPP sessions could include activities that have youth creating health-friendly point-of-purchase labels for convenience store foods that are high in fiber and whole grains and low in fat, sugar, and calories. Youth could also put on weekly taste tests at the stores that feature healthy foods, as well as create posters and advertisements featuring healthy snacks and beverages.

Although focus group and interview participants agreed that mind-set and attitude toward eating unhealthy foods was a barrier to changing eating behaviors in youth, there was strong support to translate the DPP sessions to teach healthy nutrition habits at a young age. This study's finding that diabetes prevention education needs to start at an early age is similar to studies in which focus group participants thought youth should be included in the lifestyle modification program for long-term impact ${ }^{36}$ and that longer lasting effects would occur if children were brought up with a basic understanding of healthy lifestyles. ${ }^{46}$ Unlike other studies, the participants in this study did not identify peer pressure, ${ }^{48}$ self-esteem issues, ${ }^{51}$ or body image (concerns about being too fat, skinny, or short) ${ }^{50}$ as influencing food choices or exercise habits in youth on the reservations, although the questions asked did not probe these specific areas.

Participants suggested incorporating a variety of activities into the lifestyle modification program for AI youth. These activities included organized sports such as flag football and golf; traditional activities such as berry picking, nature walks, gardening, horseback riding, and dancing; and seasonal activities such as hunting, hiking, camping, sledding, skiing, and winter hockey. While some participants thought too much emphasis was put on basketball on the reservation, successful athletes may provide important role models for youth who are not very active. These athletes could come to a DPP session and talk about the importance of physical activity in preventing risk for diabetes.

Participants thought it was important to include cultural components for healthy behaviors for youth. Thus, the translated DPP could have community elders teaching youth to put up traditional sweat lodges and facilitate group sessions for harvesting native ceremonial grasses and berries, drying meat, and tanning hides. Similar to previous study findings, $37,46,47,52,53$ the current study suggests that community members find it imperative to maintain and include traditions and cultural preferences in diabetes prevention strategies and programs. This study determined that administering the translated DPP for youth in small groups was the most acceptable format for the tribal communities in this study. This program delivery format has been identified ${ }^{34,36,46}$ and implemented ${ }^{32,37}$ in studies using 
focus groups to translate lifestyle modification programs to diverse populations at risk for diabetes. Non-focus group-based DPP translational studies have also translated the original, individual DPP to a group-based program format. ${ }^{25-27,30}$

It would be difficult to incorporate all the participant suggestions into the translated DPPfor-youth program. For instance, some of the suggestions for improving the physical environment (eg, lack of sidewalks, getting rid of snakes on walking paths, removing toxic chemicals from local rivers and lakes) are clearly beyond the scope of the DPP adaptations. The environmental constraints identified in this study are similar to others exploring barriers to physical activity, which reported adults or youth do not go outside to exercise due to safety reasons, ${ }^{34,46,48,49,51}$ lack of sidewalks, ${ }^{46}$ lack of playground equipment, $, 88,49$ pollution, ${ }^{48}$ or lack of knowledge about using exercise equipment in the gym. ${ }^{34,46}$ Nonetheless, knowing these barriers and concerns, community members could mobilize to advocate for safer walking routes and more green space areas for volleyball, baseball, soccer, and similar sports be available for youth living on the reservation. Similar efforts could occur for finding ways to clean up environmental waste in rivers and streams so that recreation in these areas is more enjoyable and safer.

The focus groups and interviews were one phase of the CBPR study that translated the adult DPP to youth. True to the CBPR process, the community and academic research partners and $\mathrm{CAB}$ members discussed the findings from the focus groups and interviews before implementing the pilot test for the translated DPP-for-youth program in the reservation communities.

\section{Strengths and Limitations}

Interviewers were community members, which may have made it more comfortable for focus group and interview participants to disclose sensitive information. On the other hand, some participants may have been hesitant to disclose information because of familial hierarchical structures. It is difficult to know whether the facilitator's standing in the community influenced the exchange of information. The study had equal representation for both genders, and a diversity of people interested in youth health participated in the study. The authors sensed that saturation was achieved on themes related to diabetes prevention, physical activity, and diet. A limitation of the study was that not all focus groups and interviews were recorded, and thus these data relied on discussion summaries prepared by facilitators at the end of the discussions. It is also difficult to generalize the findings from these 2 communities to the more than 550 federally recognized tribes as each tribal community has its own unique cultural heritage, history, and tribal structure.

\section{Conclusions and Applications}

The study findings demonstrate the importance of engaging community members to identify strategies inherent in their culture, tradition, and environment that could effectively translate the DPP to Montana Indian youth living in rural reservation communities. This formative phase of the CBPR process helped to continue building community capacity for the future DPP intervention in Northern Plains Indian youth and further strengthen the research partnership. This methodology may prove useful to diabetes educators seeking ways to successfully implement disease prevention strategies in underserved minority populations.

\section{Acknowledgments}

Study funded by The National Institute of Diabetes, Digestive and Kidney Disease grant number R34DK7446. The authors thank the focus group and interview participants and Priscilla Friede, Todd Wilson, and KaChina Ralston for their help on this study. 


\section{References}

1. Sharma AJ, Grummer-Strawn LM, Dalenius K, et al. Obesity prevalence among low-income, preschool-aged children-United States, 1998-2008. MMWR. 2009; 58:769-773. [PubMed: 19629026]

2. Noonan C, Brown B, Bentley B, et al. Variability in childhood asthma and body mass index across Northern Plains American Indian communities. J Asthma. 2010; 47:496-500. [PubMed: 20560824]

3. Zephier E, Himes JH, Story M, Zhou X. Increasing prevalence of overweight and obesity in Northern Plains American Indian children. Arch Pediatr Adolesc Med. 2006; 160:34-39. [PubMed: 16389208]

4. Gohdes D, Oser CS, Harwell TS, Moore KR, McDowall JM, Helgerson SD. Diabetes in Montana's Indians: the epidemiology of diabetes in the Indians of the Northern Plains and Canada. Curr Diabetes Rep. 2004; 4:224-229.

5. Knowler WC, Narayan KM. Prevention of non-insulin-dependent diabetes mellitus. Prev Med. 1994; 23:701-703. [PubMed: 7845942]

6. Story M, Stevens J, Himes J, et al. Obesity in American-Indian children: prevalence, consequences, and prevention. Prev Med. 2003; 37:S3-S12. [PubMed: 14636804]

7. Acton KJ, Burrows NR, Moore K, Querec L, Geiss LS, Engelgau MM. Trends in diabetes prevalence among American Indian and Alaska Native children, adolescents, and young adults. Am J Public Health. 2002; 92:1485-1490. [PubMed: 12197981]

8. Burrows NR, Geiss LS, Engelgau MM, Acton KJ. Prevalence of diabetes among Native Americans and Alaska Natives, 1990-1997: an increasing burden. Diabetes Care. 2000; 23:1786-1790. [PubMed: 11128353]

9. Fagot-Campagna A, Pettitt DJ, Engelgau MM, et al. Type 2 diabetes among North American children and adolescents: an epidemiologic review and a public health perspective. J Pediatr. 2000; 136:664-672. [PubMed: 10802501]

10. Gohdes DM. Diabetes in American Indians: a growing problem. Diabetes Care. 1986; 9:609-613. [PubMed: 3803152]

11. Gohdes, DM.; Acton, KJ. Diabetes mellitus and its complications. In: Rhoades, ER., editor. American Indian Health: Innovations in Health Care, Promotion and Policy. Baltimore: Johns Hopkins University Press; 2000. p. 221-243.

12. Bourn DM, Mann JI, McSkimming BJ, Waldron MA, Wishart JD. Impaired glucose tolerance and NIDDML does a lifestyle intervention program have an effect? Diabetes Care. 1994; 17:13111319. [PubMed: 7821173]

13. Eriksson KF, Lindgarde F. Prevention of type 2 (non-insulin-dependent) diabetes mellitus by diet and physical exercise: the 6-year Malmö feasibility study. Diabetologia. 1991; 34:891-898. [PubMed: 1778354]

14. Knowler WC, Barrett-Connor E, Fowler SE, et al. Reduction in the incidence of type 2 diabetes with lifestyle intervention or metformin. N Engl J Med. 2002; 346:393-403. [PubMed: 11832527]

15. Page RC, Harnden KE, Cook JT, Turner RC. Can lifestyles of subjects with impaired glucose tolerance be changed? A feasibility study. Diabetes Med. 1992; 9:562-566.

16. Pan XR, Li GW, Hu YH, et al. Effects of diet and exercise in preventing NIDDM in people with impaired glucose tolerance. The Da Qing IGT and Diabetes Study. Diabetes Care. 1997; 20:537544. [PubMed: 9096977]

17. Tuomilehto J, Lindstrom J, Eriksson JG, et al. Prevention of type 2 diabetes mellitus by changes in lifestyle among subjects with impaired glucose tolerance. N Engl J Med. 2001; 344:1343-1350. [PubMed: 11333990]

18. Coleman KJ, Tiller CL, Sanchez J, et al. Prevention of the epidemic increase in child risk of overweight in low-income schools: the El Paso coordinated approach to child health. Arch Pediatr Adolesc Med. 2005; 159:217-224. [PubMed: 15753263]

19. Lytle LA, Stone EJ, Nichaman MZ, et al. Changes in nutrient intakes of elementary school children following a school-based intervention: results from the CATCH Study. Prev Med. 1996; 25:465-477. [PubMed: 8818069] 
20. Harwell TS, Gohdes D, Moore K, McDowall JM, Smilie JG, Helgerson SD. Cardiovascular disease and risk factors in Montana American Indians and non-Indians. Am J Prev Med. 2001; 20:196-201. [PubMed: 11275446]

21. Harwell TS, Moore K, McDowall JM, Helgerson SD, Gohdes D. Cardiovascular risk factors in Montana American Indians with and without diabetes. Am J Prev Med. 2003; 24:265-269. [PubMed: 12657346]

22. Moore KR, Harwell TS, McDowall JM, Helgerson SD, Gohdes D. Three-year prevalence and incidence of diabetes among American Indian youth in Montana and Wyoming, 1999 to 2001. J Pediatr. 2003; 143:368-371. [PubMed: 14517522]

23. The Diabetes Prevention Program. Design and methods for a clinical trial in the prevention of type 2 diabetes. Diabetes Care. 1999; 22:623-634. [PubMed: 10189543]

24. Garfield SA, Malozowski S, Chin MH, et al. Considerations for diabetes translational research in real-world settings. Diabetes Care. 2003; 26:2670-2674. [PubMed: 12941736]

25. Ackermann RT, Finch EA, Brizendine E, Zhou H, Marrero DG. Translating the Diabetes Prevention Program into community. The DEPLOY Pilot Study. Am J Prev Med. 2008; 35:357363. [PubMed: 18779029]

26. Kramer MK, Kriska AM, Venditti EM, et al. Translating the Diabetes Prevention Program: a comprehensive model for prevention training and program delivery. Am J Prev Med. 2009; 37:505-511. [PubMed: 19944916]

27. McBride PE, Einerson JA, Grant H, et al. Putting the diabetes prevention program into practice: a program for weight loss and cardiovascular risk reduction for patients with metabolic syndrome of type 2 diabetes mellitus. J Nutr Health Aging. 2008; 12:745S-749S. [PubMed: 19043651]

28. McTigue KM, Conroy MB, Bigi L, Murphy C, McNeil M. Weight loss through living well: translating an effective lifestyle intervention into clinical practice. Diabetes Educ. 2009; 35:199_ 208. [PubMed: 19321806]

29. Whittemore R, Melkus G, Wagner J, Dziura J, Northrup V, Grey M. Translating the Diabetes Prevention Program to primary care. Nurs Res. 2009; 58:2-12. [PubMed: 19092550]

30. Amundson HA, Butcher MK, Gohdes D, et al. Translating the Diabetes Prevention Program in practice in the general community: findings from the Montana cardiovascular disease and prevention program. Diabetes Educ. 2009; 35:209-223. [PubMed: 19321807]

31. Seidel MC, Powell RO, Zgibor JC, Siminerio LM, Piatt GA. Translating the Diabetes Prevention Program into an urban medically underserved community. Diabetes Care. 2008; 31:684-689. [PubMed: 18252904]

32. Boltri JM, Davis-Smith M, Seale JP, Shellenberger S, Okosun IS, Cornelius ME. Diabetes prevention in a faith-based setting: results of translational research. J Public Health Manag Pract 2008; 14:29-32. [PubMed: 18091037]

33. Davis-Smith M. Implementing a diabetes prevention program in a rural African-American church. J Nat Med Assoc. 2007; 99:440-446.

34. Punzalan C, Paxton KC, Guentzel H, et al. Seeking community input to improve implementation of a lifestyle modification program. Ethn Dis. 2006; 16:79-88.

35. Ackermann RT, Marrero DG. Adapting the Diabetes Prevention Program lifestyle intervention for delivery in the community: the YMCA model. Diabetes Educ. 2007; 33:73-78.

36. Boltri JM, Davis-Smith M, Zayas LE, et al. Developing a church-based Diabetes Prevention Program with African Americans: focus group findings. Diabetes Educ. 2006; 32:901-909. [PubMed: 17102157]

37. Massaro E, Clalborne N. Effective strategies for reaching high-risk minorities with diabetes. Diabetes Educ. 2001; 27:820-828. [PubMed: 12211923]

38. Israel BA, Schulz AJ, Parker EA, Becker AB. Review of community-based research: assessing partnership approaches to improve public health. Annu Rev Public Health. 1998; 19:173-202. [PubMed: 9611617]

39. Israel BA, Schulz AJ, Parker EA, Becker AB. Community-based participatory research: policy recommendations for promoting a partnership approach in health research. Educ Health. 2001; 14:182-197. 
40. Brown B, Noonan C, Bentley B, et al. Acanthosis Nigricans among Northern Plains American Indian children. J Sch Nurs. Jul 1.2010 [Epub ahead of print].

41. US Census Bureau. Census 2000. Washington, DC: US Census Bureau; 2001.

42. Office of Public Instruction. Montana School Nutrition Programs Free and Reduced Price Participation Data. Helena, MT: Office of Public Instruction; 2005.

43. Glaser, B.; Strauss, A. The Discovery of Grounded Theory: Strategies for Qualitative Research. Chicago: Aldine; 1967.

44. Cohen J. A coefficient of agreement for nominal scales. Educ Psychol Meas. 1960; 20:37-46.

45. Landis JR, Koch GG. The measurement of observer agreement for categorical data. Biometrics. 1977; 33:159-174. [PubMed: 843571]

46. Satterfield DW, Lofton T, May JE, et al. Learning from listening: common concerns and perceptions about diabetes prevention among diverse American populations. J Public Health Manag Pract. 2003; 9:S56-S63. [PubMed: 14677332]

47. Bisset S, Cargo M, Delormier T, Macaulay AC, Potvin L. Legitimizing diabetes as a community health issue: a case analysis of an aboriginal community in Canada. Health Promot Int. 2004; 19:317-326. [PubMed: 15306616]

48. Hesketh K, Walters E, Green J, Salmon L, Williams J. Healthy eating, activity and obesity prevention: a qualitative study of parent and child perceptions in Australia. Health Promot Int. 2005; 20:19-26. [PubMed: 15668217]

49. Monge-Rojas R, Garita-Arce C, Sanchez-Lopez M, Colon-Ramos U. Barriers to and suggestions for a healthful, active lifestyle as perceived by rural and urban Costa Rican adolescents. J Nutr Educ Behav. 2009; 41:152-160. [PubMed: 19411048]

50. Neumark-Sztainer D, Story M, Perry C, Casey MA. Factors influencing food choices of adolescents: findings from focus-group discussions with adolescents. J Am Diet Assoc. 1999; 99:929-937. [PubMed: 10450307]

51. Styles JL, Meier A, Sutherland LA, Campbell MK. Parents' and caregivers' concerns about obesity in young children: a qualitative study. Fam Community Health. 2007; 30:279-295. [PubMed: 17873635]

52. Satterfield DW, Volansky M, Caspersen CJ, et al. Community-based lifestyle interventions to prevent type 2 diabetes. Diabetes Care. 2003; 26:2643-2652. [PubMed: 12941733]

53. Macaulay AC, Paradis G, Potvin L, et al. The Kahnawake Schools Diabetes Prevention Project: intervention, evaluation, and baseline results of a diabetes primary prevention program with a native community in Canada. Prev Med. 1997; 26:779-790. [PubMed: 9388789] 
Table 1

Suggested Activities for the Communities

\begin{tabular}{|ll|}
\hline Organized sports & Native activities \\
Intramural basketball & Berry picking \\
Flag football & Searching for herbs \\
Longer basketball season & Nature walks \\
Softball & Gardening, including growing sweet grass \\
Bowling & \\
Walking clubs & Native American games \\
Golf & Horseback riding \\
Volleyball & Chopping wood \\
Winter activities & Dancing \\
Winter hockey & Summer activities \\
Sledding & Hunting \\
Skiing & Hiking \\
Snowball fights & Camping \\
& Bike riding \\
\hline
\end{tabular}

